\section{Assessment effect of breast milk on diaper dermatitis}

\author{
Bahar Seifi, ${ }^{1}$ Sheida Jalali, ${ }^{2}$ \\ Mohammad Heidari ${ }^{3}$ \\ ${ }^{1}$ Department of Nursing, Tehran \\ Medical Sciences Branch, Islamic Azad \\ University, Tehran; ${ }^{2}$ Department of \\ Midwifery, Tehran Medical Sciences \\ Branch, Islamic Azad University, \\ Tehran; ${ }^{3}$ Department of Medical and \\ Surgical, School of Nursing and \\ Midwifery, Shahrekord University of \\ Medical Sciences, Shahrekord, Iran
}

\begin{abstract}
Diaper dermatitis is the most common dermatological disease of infancy, which occurs and caused by the combined effect of irritants such as diaper, urine and faces. In this study, we intend to evaluate the effect of breast milk on the healing of diaper dermatitis. This study was a clinical trial of 30 infants between 0-12 months of age that were suffering from diaper dermatitis and referred to the Health Centers in Tehran, Iran. The subjects were selected by open study. Infants were divided into two matched groups: case and control. Datagathering tools were the questionnaire that contained two parts: the demographic characteristics of infants and the status of care and condition of the lesion. Data analysis was performed using SPSS/18 software and Mann-Whitney and Chi-Square tests were used. The findings revealed a significant difference between the case and control groups in the number and lesion score of the rashes at the first and third day $(\mathrm{P}=0.013$, $\mathrm{P}=0.005)$, these differences were more significant at the fifth day $(\mathrm{P}=0.004, \mathrm{P}=0.001)$. Because of positive effects of breast milk on healing of diaper dermatitis, it is proposed that educational programs in health centers should be considered by health officials, and the managers would play a key role in increasing knowledge behavior changes in mothers.
\end{abstract}

\section{Introduction}

Diaper dermatitis is the most common dermatological problem of infancy. ${ }^{1}$ The diagnosis is based on the clinical observation, characterized by an acute inflammatory eruption of the skin in the diaper area of an infant. Although this condition is relatively common, it can cause considerable pain and stress for infants and could be troublesome for their caregivers. ${ }^{2,3}$ In the United States, the frequency of diaper dermatitis is substantial and accounts for a high number of health care visits. The three most common types of diaper dermatitis are: chafing dermatitis, irritant contact dermatitis and diaper candidacies. ${ }^{4}$ Diaper dermatitis is also known as diaper rash or nappy rash, indicating inflammation of the skin in the area covered by diapers. Diaper dermatitis commonly occurs in general pediatric practice, occurring in $16 \%$ of children with a primary or a secondary skin complaint. ${ }^{4}$ An estimated $7 \%$ to $35 \%$ of the infant population is affected at a given time, with the highest prevalence in infants 9 to 12 months of old. Only $7 \%$ of diaper dermatitis cases seek medical advice. On the other hand, a group of skin disorders that result from attack of the skin by physical, chemical, enzymatic, and microbial factors result in the diaper environment. ${ }^{5}$ The integrity of healthy skin is compromised by the very nature of the diaper environment, and normal intact skin. Therefore, remains an elusive goal of current diapering practices. Moist occlusion promotes malaria, and causes an increase in the coefficient of skin friction. ${ }^{6}$ Diapering is unquestionably an effective and convenient way of localizing an infant's excreta. Unfortunately, infant skin was not designed to operate continuously in the resulting environment, and is frequently unable to whether this assault. ${ }^{7} \mathrm{~A}$ diverse group of diseases can cause skin conditions in the diaper area, including those which are directly caused by diapers or the diaper environment, some which are not clearly due to, but are worsened by, the wearing of diapers, and those which are independent of the presence of the diaper or its resulting environment. ${ }^{8}$ Many of these conditions are limited to this area of the skin, but others extend to skin outside this area, and some are signs of systemic disease. The most important factors in the development of diaper dermatitis are: water/moisture, friction, urine, feces, and microorganisms (sometimes). ${ }^{9}$ Diaper rash affects the areas within the confines of the diaper. Increased wetness in the diaper area makes the skin more susceptible to damage by physical, chemical, and enzymatic mechanisms. Wet skin increases the penetration of irritant substances. ${ }^{10}$ However, Breast milk does appear to have healing properties that can prove beneficial when it comes to treating minor illnesses and injuries. This is due to the antibodies that breast milk contains. It can kill off bacteria and viruses when applied topically to problematic areas because of antibacterial properties. ${ }^{11}$ It is important to distinguish diaper
Correspondence: Mohammad Heidari, Department of Medical and Surgical, School of Nursing and Midwifery, Shahrekord University of Medical Sciences, Shahrekord, Iran.

Tel.: +98.9131850128.

E-mail: heidari@skums.ac.ir

Key words: Breast milk; dermatitis healing; diaper dermatitis.

Acknowledgments: this paper is the result of a research project supported by the Tehran Medical Sciences Branch, Islamic Azad University research project.

Contributions: BS, idea conceiving; BS, SJ, $\mathrm{MH}$, data collection; $\mathrm{MH}$ data interpretation. All authors contributed equally in drafting and editing the manuscript.

Conflict of interest: the authors declare no potential conflict of interest.

Received for publication: 11 January 2017. Accepted for publication: 23 February 2017.

This work is licensed under a Creative Commons Attribution-NonCommercial 4.0 International License (CC BY-NC 4.0).

(C) Copyright B. Seifi et al., 2017

Licensee PAGEPress, Italy

Dermatology Reports 2017; 9:7044

doi:10.4081/dr.2017.7044

dermatitis from other dermatomes that may develop within the diaper area. Considerable advances have occurred during recent years in the scientific knowledge regarding the benefits of breastfeeding, the mechanisms underlying these benefits, and in the clinical management of breastfeeding diaper. ${ }^{12}$ Studies show human breast milk as a preventive measure and effective treatment of some sores and infections. ${ }^{13}$ These are all conditions that mother's milk is cheap and readily available, side effects and contraindications, not even anti-bacterial and regenerative properties. ${ }^{14}$ In addition to feeding, such as greater use: conjunctivitis, sore nipples, ear infection, diaper rash that there is oriented to the milk as a topical antibacterial agent in the treatment and healing effect. ${ }^{15}$ For century's breast milk as a natural substance used smooth skin. Breast milk contains vitamin groups: A, E, D, K and B complex, vitamin $\mathrm{E}$ is that it is very effective. ${ }^{16}$ Breastfeeding lead to skin cream. Furthermore it is a natural substance that causes softness to the skin. Research has shown that protein, calcium and vitamin B12 in milk play an important role in the prevention of complications such as dry skin, eczema and its fragility. ${ }^{17}$ The lactic acid in milk is used in most skin creams and 
lotions, face and softening effect upon the skin. There is some evidence that ingestion of breast milk protects the infant against certain infectious and non-infectious conditions. ${ }^{18}$ It is important that midwives are aware of current evidence to inform the advice they give to women on infant feeding. ${ }^{19}$ According to the above this study was conducted with the aim of assessing the effect of breast milk on diaper dermatitis.

\section{Materials and Methods}

This study was a clinical trial of 30 infants between $0-12$ months of age that were suffering from diaper dermatitis and referred to the Health Centers in Tehran, Iran. Ethical committee approval was obtained for this HIPAA compliant clinical trial. Thirty infants with diaper dermatitis sought medical advice at our health centers within three months. We planned that thirty infants were recruited for this study. After full explanation of the goals, informed consent was obtained from the caregivers. A through medical history was obtained and a complete physical examination was conducted to rule out any other possible cause of dermatitis. The exclusion criteria were presence of infection or candidacies. However we did not exclude any patient. Infants were randomly assigned to case $(n=15)$ and control $(n=15)$ groups and were matched by age, sex, parent's job, family income, number of diaper change per day, number of rashes and dermatitis score (lesion score). Both groups were followed up for five days (visits on first, third and fifth days of the intervention). Data were collected by a questionnaire, which contained two parts: demographic and state of care. Demographic data were filled through an interview with mothers on the first day. The state of care included number of the lesions, location, and severity of erythema, which was scored according to Al-Waili study; a five-point scale rash severity:
$0=$ None, $1=$ Mild erythema, $2=$ Moderate erythema, $3=$ Moderate erythema + maceration, 4=Sever erythema + pustules or ulceration. ${ }^{20}$ The second part of the questionnaire was filled by a research assistant on days 1 , 3 and 5. During study, any new signs or symptoms were recorded. A positive therapeutic effect was described as score improvement such as when a moderate rash became mild or a mild rash disappeared. The mothers in the control group were asked to bath the infant following urination or defecation with only warm water, pat them dry and change diapers. They were asked not to apply any topical treatment or creams. In the case group, mothers were instructed to do the same in addition to applying breast milk three times a day on the affected area and let it air dry before putting a diaper back on. All mothers used the same brand of diapers before and during the study. Lesions that did not improve within five days of the study were treated with conventional therapy, and the failure was recorded. No other topical products were used during the study period. Data were analyzed using the SPSS package 18.0 for Windows (SPSS, Chicago, IL, USA). Chi-Square test was used to assess the differences between case and control groups.

\section{Results}

Thirty number of infants were included in the study with the six months of mean age. All infants were breast feeder, used high-power absorbent cloths for diapering, and none used disposable diapers. Infants' demographic characteristics were shown on Table 1. Most of infants had the first birth seniority. All the mothers were housewives and $53.3 \%$ of the fathers had private jobs. The mean family salary was between 300 450 dollars. About 30\% mothers and 33.3\% fathers had (a qualification of) diploma or higher. The mean ages of mothers were 25.44 years and mean ages of fathers were
30.5. All infants were breast feeder and all of them were used cloth diapers (high power absorbent material) for diapering and none of them used disposable diapers. Nobody used soaps and powders. Frequency of diaper changes in $60 \%$ cases was 6 times/day. No sexual difference was observed. Diaper rashes were most common between 8-10 months old.

About $73.3 \%$ infants have one site of diaper rash. The mean and standard deviation of number of dermatitis were shown in Table 2. $60 \%$ of infants have moderate rash (according to Al-Waili study; ${ }^{20}$ a five-point scale rash severity). Table 3 was shown number, location and score of lesions in case and control group. In the case group, $73.3 \%$ had two dermatitis with moderate erythema and $53.3 \%$ of the control group had one lesion with mild erythema. The mothers reported breast milk application as convenient.

Out of 15 infants with score 1or 2 (mild or moderate erythema) in case group, $80 \%$ improved during the study period in fifth day. In control group $26.1 \%$ infants showed improvement. In case group the mean of scores pre and post intervention showed a significant difference $(\mathrm{P}=0.006)$ while in control group no difference was detected.

Most common locations for dermatitis rash in days 1 and 3 were anal (66\%), genitalia $(10 \%)$ and perineum $(6 \%)$ regions.

The topical application of the breast milk has decreased the incidence of anal dermatitis rash $(\mathrm{P}=0.009) .80 \%$ of infants in case group have been none erythema and $20 \%$ failed to respond to breast milk application with mild erythema. $73.3 \%$ of infants in the control group placed on conventional therapy at the end of 5-day study (Figure 1).

\section{Discussion}

Physical degradation of the epidermal barrier caused by exposure to excrement, moisture, and friction directly contributes to

Table 1. Demographics characteristics in infants.

\begin{tabular}{|c|c|c|c|}
\hline Variations & Case $(n=15)$ & Control $(\mathrm{n}=15)$ & Results \\
\hline Age & $>6$ months: $60 \%$ & $<6$ months: $60 \%$ & $\mathrm{~F}=0.5$ \\
\hline Sex & Boys: $53.3 \%$ & Boys: $60 \%$ & $\mathrm{~F}=0.5$ \\
\hline Parents job & $\begin{array}{l}\text { Mothers: } 100 \% \text { housewives } \\
\text { Fathers: } 53.3 \text { private jobs }\end{array}$ & $\begin{array}{l}\text { Mothers: } 100 \% \text { housewives } \\
\text { Fathers } 53.3 \text { private jobs }\end{array}$ & $\mathrm{P}=0.229$ \\
\hline Family income & Between 300-450 dollars/months & Between 300-450 dollars/months & $\mathrm{P}=0.584$ \\
\hline Diapers & $\begin{array}{l}\text { 100\% used cloth diapers } \\
\text { (high power absorbent material) }\end{array}$ & $\begin{array}{l}\text { 100\% used cloth diapers } \\
\text { (high power absorbent material) }\end{array}$ & $\mathrm{P}=0.00$ \\
\hline Number of diaper change per day & $60 \%$ six times/day & $60 \%$ six times/day & $P=0.00$ \\
\hline
\end{tabular}


diaper dermatitis. Furthermore, reduced skin acidity (of $\mathrm{pH}$ ) is associated with a decrease in epidermal barrier integrity, reduced antimicrobial defenses, and increased inflammation. ${ }^{21}$ Diaper dermatitis can cause significant discomfort for infants and distress for their parents and caregivers. $^{22}$ Ehretsmann et al. obtained similar results. ${ }^{23}$ These provide useful information regarding the comparative skin mildness of baby wipes and water. Our findings showed a significant difference between the number of dermatitis rash and lesion score on the third day as a result of topical use of the breast milk. This result is consistent with the findings of Al-Waili. ${ }^{20}$ According to Al-Waili et al., olive oil, beeswax and honey are natural products, containing flavonoids, and antioxidant, antibacterial and antifungal compounds that affect the production of cytokines by skin cells when applied topically. On the fifth day there was still obvious differences between two groups by the number of rashes and lesion score; this was consistent with the findings of Baldwin et al. ${ }^{24}$ Visscher et $a l$. noted that regular use of over the counter diaper ointments or pastes, and frequent diaper changes are required in any patient without a history of diaper dermatitis. Topical corticosteroids are still recognized as a treatment option for diaper dermatitis, although it is increasingly discouraged. ${ }^{25}$ Farahani et al. and Gozen et al. described human breast milk as an effective and safe treatment for diaper dermatitis in

Table 2. Mean and standard deviation of the number of dermatitis rash, among the study subjects.

\begin{tabular}{llccc}
\hline Local rash Groups & & First day & Third day & Fifth day \\
Case & Mean & 1.0667 & 0.6 & 0.2 \\
& Total & 15 & 15 & 15 \\
& Standard deviation & 0.2582 & 0.50709 & 0.41404 \\
Control & Mean & 1.4667 & 1.4 & 1.2667 \\
& Total & 15 & 15 & 15 \\
& Standard deviation & 0.83381 & 0.91026 & 1.2228 \\
\hline
\end{tabular}

Table 3. Compare the situation changes dermatitis rash, of study subjects in both groups.

\begin{tabular}{llccc} 
Days diaper dermatitis & & First day & Third day & Fifth day \\
Number of local rash & \multirow{2}{*}{ Case } & $86.7 \%$ & $46.7 \%$ & $80 \%$ \\
& & $\mathrm{~N}=1$ & $\mathrm{~N}=1$ & $\mathrm{~N}=0$ \\
& Control & $60 \%$ & $53.3 \%$ & $26.7 \%$ \\
& & $\mathrm{~N}=1$ & $\mathrm{~N}=1$ & $\mathrm{~N}=0$ \\
& P-value & $\mathrm{P}=0.09$ & $\mathrm{P}=0.013$ & $\mathrm{P}=0.004$ \\
Lesion score & $73.3 \%$ & $46.7 \%$ & $80 \%$ \\
& Case & Moderate & Mild & None \\
& Control & 53.3 & $60 \%$ & $26.7 \%$ \\
& & Mild & Moderate & None \\
& P-value & $\mathrm{P}=0.132$ & $\mathrm{P}=0.005$ & $\mathrm{P}=0.001$ \\
\hline
\end{tabular}

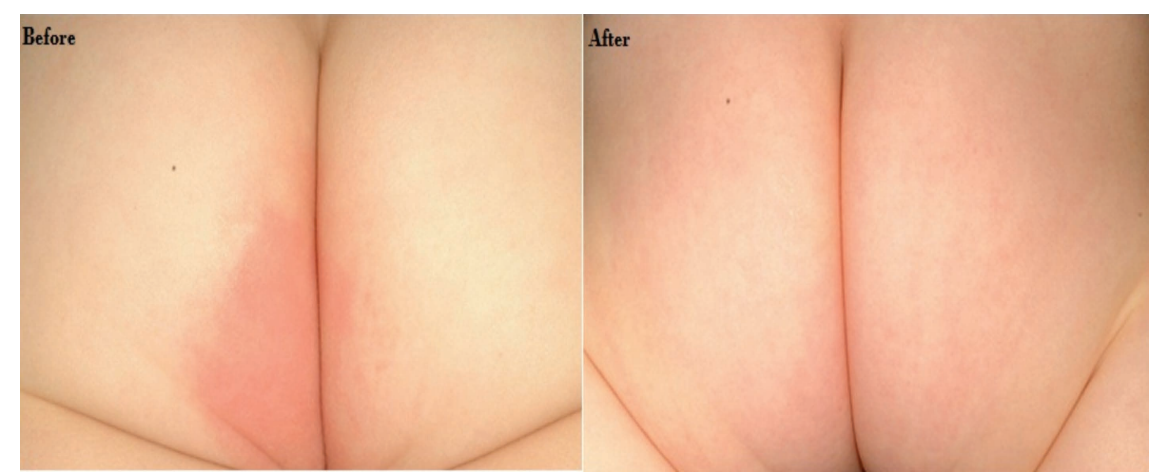

Figure 1. Diaper dermatitis anal area before and after treatment with breast milk. infants, ${ }^{11,26}$ whereas Spraker et al. recommended topical miconazole nitrate ointment for the treatment of diaper dermatitis. ${ }^{27}$

\section{Limitations}

However, regarding the results, limitation should be acknowledged. This article is limited by its emphasis on papers published in English in journal databases, so we may have missed potentially useful studies.

\section{Conclusions}

Diaper dermatitis is a stressful condition for affected infants and their caregivers. Breast milk can be an effective, safe and convenient remedy. Educational programs in primary health centers can target caregivers.

\section{References}

1. Brucker M, McGuire S, Merrill L, et al. Clinicians discuss diaper dermatitis. Nurs Women Health 2015;19:422-9.

2. Kayaoglu S, Kivanc-Altunay I, Sarikaya S. Diaper dermatitis in infants admitted to social pediatrics health center: role of socio-demographic factors and infant care. Indian $\mathrm{J}$ Pediatr 2015;82:904-8.

3. Sheikhei RA, Heydari M, Shahbazi S. Comparison of intra-abdominal pressure measurement and physical exam for diagnosis of surgery indication in patients with abdominal compartment syndrome due to blunt trauma. J Kerman Univ Med Sci 2011;18:271-8.

4. Garcia Bartels N, Lünnemann L, Stroux A, et al. Effect of diaper cream and wet wipes on skin barrier properties in infants: a prospective randomized controlled trial. Pediatr Dermatol 2014;31: 683-91.

5. Erasala G, Merlay I, Romain C. [Evolution of disposable diapers and reduction of diaper dermatitis]. Archiv Pediatr 2007;14:495-500 [In French].

6. Al-Faraidy NA, Al-Natour SH. A forgotten complication of diaper dermatitis: Granuloma gluteale infantum. J Fam Commun Med 2010;17:107.

7. Hoeger P, Stark S, Jost G. Efficacy and safety of two different antifungal pastes in infants with diaper dermatitis: a randomized, controlled study. J Eur Acad Dermatol Venereol 2010;24:1094-8.

8. Visscher MO, Chatterjee R, Ebel JP, et al. Biomedical assessment and instrumental evaluation of healthy infant skin. Pediatr Dermatol 2002;19:473-81. 
9. Ravanfar P, Wallace JS, Pace NC Diaper dermatitis: a review and update. Curr Opin Pediatr 2012;24:472-9.

10. Stamatas GN, Tierney NK. Diaper dermatitis: etiology, manifestations, prevention, and management. Pediatr Dermatol 2014;31:1-7.

11. Gozen D, Caglar S, Bayraktar S, Atici F. Diaper dermatitis care of newborns human breast milk or barrier cream. J Clin Nursing 2014;23:515-23.

12. Atherton DJ. A review of the pathophysiology, prevention and treatment of irritant diaper dermatitis. Curr Med Res Opin 2004;20:645-9.

13. Urbaniak C, Angelini M, Gloor GB, Reid G. Human milk microbiota profiles in relation to birthing method, gestation and infant gender. Microbiome 2016;4:1-9.

14 Giusti A. Breastfeeding: health, prevention, and environment. Epidemiol Prevenz 2014;39:386-91.

15. Zaheer K, Akhtar MH. An updated review of dietary isoflavones: nutrition, processing, bioavailability and impacts on human health. Crit Rev Food Sci Nutr 2015 [In press].

16. Gertosio C, Meazza C, Pagani S,
Bozzola M. Breast feeding: gamut of benefits. Minerva Pediatr 2015 [In press].

17. við Streym S, Højskov CS, Møller UK, et al. Vitamin D content in human breast milk: a 9-mo follow-up study. Am J Clin Nutr 2016;103:107-14.

18. Arnold LD, Larson E. Immunologic benefits of brest milk in relation to human milk banking. Am J Infect Control 1993;21:235-42.

19. Mehrparvar S, Varzandeh M. Investigation of decreasing causes of exclusive breastfeeding in children below six months old, in Kerman city during 2008-2009. J Fasa Univ Med Sci 2011;1:45-52.

20. Al-Waili N. Clinical and mycological benefits of topical application of honey, olive oil and beeswax in diaper dermatitis. Clin Microbiol Infect 2005;11:1603.

21. Markham T, Kennedy F, Collins P. Topical sucralfate for erosive irritant diaper dermatitis. Archiv Dermatol 2000;136:1199-200.

22. Austin AP, Milligan MC, Pennington K, Tweito DH. A survey of factors associated with diaper dermatitis in thirty-six pediatric practices. J Pediatr Health Care 1988;2:295-9.

23. Ehretsmann C, Schaefer P, Adam R. Cutaneous tolerance of baby wipes by infants with atopic dermatitis, and comparison of the mildness of baby wipe and water in infant skin. J Eur Acad Dermatol Venereol 2001;15:16-21.

24. Baldwin S, Odio M, Haines S, et al. Skin benefits from continuous topical administration of a zinc oxide/petrolatum formulation by a novel disposable diaper. J Eur Acad Dermatol Venereol 2001;15:5-11.

25. Visscher MO, Chatterjee R, Munson $\mathrm{KA}$, et al. Development of diaper rash in the newborn. Pediatr Dermatol 2000;17:52-7.

26. Farahani LA, Ghobadzadeh M, Yousefi P. Comparison of the effect of human milk and topical hydrocortisone $1 \%$ on diaper dermatitis. Pediatr Dermatol 2013;30:725-9.

27. Spraker MK, Gisoldi EM, Siegfried EC, et al. Topical miconazole nitrate ointment in the treatment of diaper dermatitis complicated by candidiasis. Cutis 2006;77:113-20. 